\title{
Damage Detection of Refractory Based on Principle Component Analysis and Gaussian Mixture Model
}

\author{
Changming Liu, ${ }^{1}$ Di Zhou, ${ }^{2}$ Zhigang Wang, ${ }^{3}$ Dan Yang, ${ }^{4}$ and Gangbing Song ${ }^{5}{ }^{5}$ \\ ${ }^{1}$ The State Key Laboratory of Refractories and Metallurgy, Wuhan University of Science and Technology, Wuhan 430081, China \\ ${ }^{2}$ Key Laboratory of Metallurgical Equipment and Control Technology, Wuhan University of Science and Technology, \\ Wuhan 430081, China \\ ${ }^{3}$ Ministry of Education, Hubei Key Laboratory of Mechanical Transmission and Manufacturing Engineering, \\ Wuhan University of Science and Technology, Wuhan 430081, China \\ ${ }^{4}$ National Demonstration Center for Experimental Machinery Education, Wuhan University of Science and Technology, \\ Wuhan 430081, China \\ ${ }^{5}$ Smart Materials and Structures Laboratory, Department of Mechanical Engineering, University of Houston, Houston, \\ TX 77204, USA
}

Correspondence should be addressed to Gangbing Song; gsong@uh.edu

Received 11 August 2017; Accepted 3 January 2018; Published 31 January 2018

Academic Editor: Michele Scarpiniti

Copyright (c) 2018 Changming Liu et al. This is an open access article distributed under the Creative Commons Attribution License, which permits unrestricted use, distribution, and reproduction in any medium, provided the original work is properly cited.

\begin{abstract}
Acoustic emission (AE) technique is a common approach to identify the damage of the refractories; however, there is a complex problem since there are as many as fifteen involved parameters, which calls for effective data processing and classification algorithms to reduce the level of complexity. In this paper, experiments involving three-point bending tests of refractories were conducted and $\mathrm{AE}$ signals were collected. A new data processing method of merging the similar parameters in the description of the damage and reducing the dimension was developed. By means of the principle component analysis (PCA) for dimension reduction, the fifteen related parameters can be reduced to two parameters. The parameters were the linear combinations of the fifteen original parameters and taken as the indexes for damage classification. Based on the proposed approach, the Gaussian mixture model was integrated with the Bayesian information criterion to group the AE signals into two damage categories, which accounted for $99 \%$ of all damage. Electronic microscope scanning of the refractories verified the two types of damage.
\end{abstract}

\section{Introduction}

Structural health monitoring (SHM) has made significant advances in the past decades [1-8]. Monitoring of refractories, which are widely used in furnace, iron, and steel industries due to their ability to gain strength rapidly and to withstand aggressive environments and high temperature [9], receives increasing attention [10-13]. Temperature variations can lead to either interfacial separation between aggregates and matrix or microcracks, both depending on the range of coefficient of thermal expansion (CTE) mismatch between phases. Such effects modify all the thermomechanical properties of the material, especially Young's modulus (E) [10, $11,14]$. The $\mathrm{AE}$ technique has been developed over the last two decades as a nondestructive evaluation technique and as a useful tool for material research [15-17]. It is an efficient method to monitor, in real time, damage growth in both structural components and laboratory specimens. This technique was often used to detect Young's modulus because it was correlated to $\mathrm{AE}$ activity variations considering the specific types of damage induced by CTE mismatch $[12,13]$. The acoustic emission technique and the ultrasonic pulse echography technique, both carried out at high temperature, were applied as nondestructive characterization methods to monitor the damage extension within the materials submitted to thermal stress and to follow the evolution of the associated elastic properties $[18,19]$. With this as a basis, the study could provide an important reference for thermal stress analysis under the $\mathrm{AE}$ data processing method. However, the $\mathrm{AE}$ signals generated by the complex structure of the refractory 
are extremely complex even at normal temperature, which makes it difficult for the damage classification [20]. For this purpose, the AE signal parameters of the delay distribution, rise time, energy, and peak amplitude were selected to distinguish the effective features for different failure mechanism so that the two failure modes of fiber breakage and delamination can be distinguished $[21,22]$. The related parameters can be modeled by a generative model, in particular a Gaussian mixture model (GMM) in the field of dimension processing $[23,24]$. The global feature descriptor was formed by stacking the parameters of the adapted GMM (i.e., means, covariance, and weight) in a so-called supervector $[25,26]$. Also, some scientists paid more attention to the parameter of the signal energy moment compared to the peak amplitude distribution in the study of the glass fiber composite materials and chose it to distinguish the fiber breakage and debonding crack. Moreover, the amplitude, ring count, and felicity ratio were found more suitable in the damage study of the B-Al composite [27]. However, much effort was put on the characterization of the overall parameters rather than on the data analysis of the damage mechanism.

Optionally, the dimensionality of the feature vectors can be reduced by a principal component analysis (PCA) [28]. The PCA was used to generate a new set of noncorrelated features to remove interference and to avoid using low variance variables (that was almost single-valued variables). Moreover, these new features were selected according to their discriminative capability. Subsequently, feature space modeling and classification were addressed by means of probabilistic selforganizing maps (SOM), a fuzzy version of classical SOM that allowed measuring the activation probability of each unit $[29,30]$. Nevertheless, detecting not only an event but also the type was not a straightforward task, and previous approaches had not been able to obtain high per attack detection accuracy values. Scientists showed that the resulting GMM supervector encoding yielded an excellent representation for fuzzy parameters [31,32]. This method was an outstanding technique for handling the description of multimodal data, making it robust with high computational efficiency [26]. Additionally, scientists employed support vector machines (SVM) to build individual classifiers per sample cluster [33, 34]. Such a SVM was a linear classifier trained by only one single positive sample and multiple negative samples; it was denoted as Exemplar-SVM. Therefore, secondly, using the features extracted by $\mathrm{AE}$, the negative log likelihood was obtained by using the Bayesian GMM which was an outstanding technique for the multimodal distribution of the data with high computational efficiency $[35,36]$. Among others, the PCA have been used successfully for object classification and scene classification. The PCA method is a statistical linear transformation selection from multiple variables to minor ones [28]. Meanwhile, the GMM is a Gauss probability density model, which can be used to accurately quantify matters and classify them into several models based on the Gauss probability density function [23].

Taking advantages of the PCA and GMM methods in the processing of the multidimensional models, especially the reduction of the $\mathrm{AE}$ parameters and pattern recognitions, this paper intends to reduce the correlation dimension of the
15 parameters of the AE signals emitted from the damage process of the materials and to obtain the two new parameters which could be used to describe the overall damage property without linear dependence. Afterwards, the GMM was used to classify the damage into two major categories. Finally, the results were verified experimentally by using scanning electron microscopy image based classification.

\section{Analysis to Construct the New Characterization}

The PCA method shows obvious advantages in the multiparameter dimension reduction problems and the construction process is clear to operate. The observation matrix of the sample is discussed by Shang et al. [37],

$$
X=\left[\begin{array}{cccc}
x & x & \cdots & x_{p} \\
x & x & \cdots & x_{p} \\
\bullet & \bullet & & \bullet \\
\bullet & \bullet & & \bullet \\
\bullet & \bullet & & \bullet \\
x_{n} & x_{n} & \cdots & x_{n p}
\end{array}\right],
$$

where the rows of the sample matrix $X$ represent the $\mathrm{AE}$ parameters and the columns correspond to different signals. The covariance matrix of the sample is

$$
s=\frac{1}{n-1} \sum_{i=1}^{n}\left(x_{i}-\bar{x}\right)\left(x_{i}-\bar{x}\right),
$$

which is the estimation of $x$. Through the calculation of $S$, the characteristic quantity of the original observation matrix can be easily reconstructed so as to facilitate the sort of the features.

Step 1. The covariance matrix of the sample is constructed by $S$ as follows:

$S$

$$
=\left[\begin{array}{cccc}
\operatorname{cov}\left(X_{1}, X_{1}\right) & \operatorname{cov}\left(X_{1}, X_{2}\right) & \cdots & \operatorname{cov}\left(X_{1}, X_{p}\right) \\
\operatorname{cov}\left(X_{2}, X_{1}\right) & \operatorname{cov}\left(X_{2}, X_{2}\right) & \cdots & \operatorname{cov}\left(X_{2}, X_{p}\right) \\
\vdots & \vdots & & \vdots \\
\operatorname{cov}\left(X_{p}, X_{1}\right) & \operatorname{cov}\left(X_{p}, X_{2}\right) & \cdots & \operatorname{cov}\left(X_{p}, X_{p}\right)
\end{array}\right]
$$

where the matrix is a $P \times P$ and positive definite matrix, and there are characteristic values of $P$ which are not equal to each other and greater than zero. Each characteristic value corresponds to a unit feature vector.

Step 2. Compute the $P$ features and its characteristic vector. Set $\lambda_{1}, \lambda_{2}, \ldots, \lambda_{p}$ to be eigenvalues of $S$. Meanwhile, $T=t_{1}, t_{2}, \ldots, t_{p}$ are the corresponding unit feature vectors. Arranging eigenvalues in a descending order gives

$$
\lambda_{1} \geq \lambda_{2} \geq \cdots \geq \lambda_{p} \geq 0 .
$$


Step 3. Define the contribution rate of the characteristic value

$$
\frac{\lambda_{i}}{\sum_{i=1}^{p} \lambda_{i}} \quad(i=1,2, \ldots, p)
$$

and the accumulated contribution rate

$$
\frac{\sum_{i=1}^{m} \lambda_{i}}{\sum_{i=1}^{p} \lambda_{i}}
$$

Step 4. Based on the principle of the accumulated contribution $\sum_{i=1}^{m} \lambda_{i} / \sum_{i=1}^{p} \lambda_{i} \geq 85 \%$, the former $m(m \leq P)$ principal components are picked, which means the former $m$ mutually orthogonal eigenvector matrices are retained.

$$
A=\left(t_{1}, t_{2}, \ldots, t_{m}\right) .
$$

Step 5. Conduct linear correlation transformation between the new feature vector matrix and the original one. In this way, the original $P$ dimension index will be reduced to $m$, which contains the ultimate information with mutual linear independence.

\section{Classification with GMM}

The GMM probability density function is set as follows:

$$
p(x)=\sum_{k=1}^{M} \omega_{k} p_{k}(x)=\sum_{k=1}^{M} \omega_{k} N\left(x \mid \mu_{k}, \sum_{k}\right) \text {, }
$$

where $M$ is the mixed number of the model; $\omega_{k}$ is the weighting coefficient of the model, and $\sum \omega_{k}=1 ; N(x \mid$ $\left.\mu_{k}, \sum_{k}\right)$ is the $k$ th single Gauss probability density function, which is depicted as

$$
N=\left(x \mid \mu, \sum\right)=\frac{e^{-(1 / 2)(x-\mu)^{T} \sum^{-1}(x-\mu)}}{(2 \pi)^{n / 2}\left|\sum\right|^{1 / 2}} .
$$

The proper parameters were evaluated as

$$
\begin{aligned}
\theta & =\left[\omega_{1}, \omega_{2}, \omega_{3}, \ldots, \omega_{M}, \mu_{1}, \mu_{2}, \mu_{3}, \ldots, \mu_{M}, \sum_{1}, \sum_{2}, \sum_{3}, \ldots,\right. \\
& \left.\sum_{M}\right]
\end{aligned}
$$

which makes the max maximum likelihood estimator of the probability density function,

$$
\begin{aligned}
J(\theta) & =\ln \left[\prod_{i=1}^{M} p(x)_{i}\right]=\sum_{i=1}^{M} \ln p\left(x_{i}\right) \\
& =\sum_{k=1}^{M} \ln \left[\omega_{k} N\left(x \mid \mu_{k}, \sigma_{k}^{2}\right)\right] .
\end{aligned}
$$

In order to obtain the maximum likelihood estimate, the GMM will be evaluated by the maximum expected value algorithm. The iteration steps are as follows.
Step 1. Initiate the parameters:

(1) Set the mean values to be random values.

(2) Set the covariance matrix $\sum \sum \sum \cdots \sum_{M}$ to be the unit matrix.

(3) Set the weighting coefficient $\omega_{1}, \omega_{2}, \omega_{3}, \ldots, \omega_{M}$ of each model to be the prior probability of each model:

$$
\omega_{i}=\frac{1}{M}
$$

where $M$ was the number of GMM.

Step 2. Compute the prior probability of each item in the model:

$$
\operatorname{Pr}\left(i \mid x_{t}, \theta^{k}\right)=\frac{\omega_{k} N\left(x_{t} \mid \mu_{i}^{k}, \sum_{i}^{k}\right)}{\sum_{k=1}^{M} \omega_{k} N\left(x_{t} \mid \mu_{i}^{k}, \sum_{i}^{k}\right)} .
$$

Step 3. Update the parameters by the prior probability:

$$
\begin{aligned}
\omega_{i}^{k+1} & =\frac{1}{T} \sum_{t=1}^{T} \operatorname{Pr}\left(i \mid x_{t}, \theta^{k}\right) . \\
\mu_{i}^{k+1} & =\frac{\sum_{t=1}^{T} \operatorname{Pr}\left(i \mid x_{t}, \theta^{k}\right) x_{t}}{\sum_{t=1}^{T} \operatorname{Pr}\left(i \mid x_{t}, \theta^{k}\right)} \\
\sum_{i}^{k+1}= & \frac{\left(\sum_{t=1}^{T} \operatorname{Pr}\left(i \mid x_{t}, \theta^{k}\right)\left(x_{t}-\mu_{i}^{k+1}\right)\left(x_{t}-\mu_{i}^{k+1}\right)^{T}\right)}{\sum_{t=1}^{T} \operatorname{Pr}\left(i \mid x_{t}, \theta^{k}\right)}
\end{aligned}
$$

Step 4. Repeat Steps 2 and 3 until the convergence:

$$
\left|\theta^{t+1}-\theta^{t}\right|<\varepsilon
$$

where $\theta^{t+1}$ and $\theta^{t}$ are the parameters estimation of the previous and current step and $\varepsilon$ is the set threshold, which is usually set to $10^{-5}$.

\section{Experimentation and Verification}

4.1. Specimens and Experiment Setup. The industrial refractory tested in the study is composed of magnesia aggregates, carbon binder (phenolic resin and/or pitch), and other components. Figure 1 shows the microstructure of such a refractory without damage. The magnesia aggregates are formed by sintering of crystallites with weak interfaces. The size of magnesia grains varies from less than one half millimeters to five millimeters. The other grains impurities, such as $\mathrm{SiO} 2$ and $\mathrm{Al} 2 \mathrm{O} 3$, with less than $5 \mathrm{~mm}$ sizes, are founded scattered in the matrix, the carbon binder.

The components were mixed and shaped into bricks at low temperature $\left(20 \sim 50^{\circ} \mathrm{C}\right)$ and under high pressure (150 $\mathrm{MPa}$ around) [12]. Then the bricks undergo heat treatment $\left(100 \sim 200^{\circ} \mathrm{C}\right)$ to start the polymerization of resin and to eliminate residual water and phenols [12]. Under these sintering conditions, we directly obtain three specimens with a rectangular cross-section of $140 \mathrm{~mm} \times 25 \mathrm{~mm} \times 25 \mathrm{~mm}$. Table 1 provides the composition of the materials after the heat treatment. 
TABLE 1: The composition of magnesia carbon refractory.

\begin{tabular}{|c|c|c|c|c|c|}
\hline \multicolumn{4}{|c|}{ Chemical composition, \% (weight) } & \multicolumn{2}{|c|}{ Phase composition, \% (volume) } \\
\hline $\mathrm{MgO}$ & $\mathrm{C}$ & $\mathrm{SiO}_{2}$ & $\mathrm{Al}_{3} \mathrm{O}_{3}$ & Aggregate phase & Continuous phase \\
\hline 82.95 & 13.07 & 0.72 & 0.61 & 65 & 35 \\
\hline
\end{tabular}

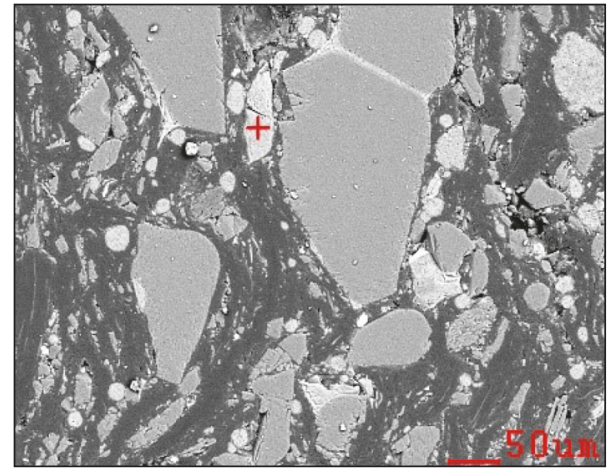

FIGURE 1: Typical microstructure of magnesia carbon refractory.

According to ASTM C1161-13 [38], the shape of the samples for 3-point bending should be rectangular and the size of the samples should be 3 by 4 by 45 to $50 \mathrm{~mm}$ minimum with $40 \mathrm{~mm}$ outer span 3-point bending. Therefore, the specimens were prepared to be $140 \mathrm{~mm} \times 25 \mathrm{~mm} \times 25 \mathrm{~mm}$. The 3-point bending tests were performed using a HMOR/STRAIN loading machine. The crosshead speed of the machine was fixed at $0.05 \mathrm{~mm} / \mathrm{min}$. The tests were executed on three specimens of each configuration in order to ensure the accuracy of the results (Figure 2).

$\mathrm{AE}$ is defined as phenomena whereby transient elastic waves are generated by the rapid release of energy from localized sources within a material (or structure). The $\mathrm{AE}$, which represents the generation of transient ultrasonic waves due to damage development within the material under load, is an efficient technique for structural health monitoring, as discussed elsewhere [39-41]. When a material is subjected to solicitations (such as mechanical and thermal), acoustic emission can be generated by a variety of sources, including crack nucleation and propagation, multiple dislocation slip, twinning, grain boundary sliding, phase transformations in alloys, debonding of grain in composite materials, or fracture of inclusions in alloys. This technique has been used at either the laboratory level or industrial scale. Usually, this technique is applied at room temperature as a nondestructive characterization technique in order to follow in real time the evolution of the damage of a material subjected to mechanical loading. Here, the upper surface of the sample should be slightly polished to remove the burr in order to locate the $\mathrm{AE}$ sensor. Then the coupling agent was coated on the polished zone and the AE sensor was fixed on the coupling agent surface with the adhesive tape. The stress wave was passed from the surface of the sample to the $\mathrm{AE}$ sensor through the coupling agent. The application of $\mathrm{AE}$ technique aims to characterize the material microdamage at a very local scale.

The device of acquisition (Figure 3 ) is composed of a wide band $(175 \mathrm{kHz} 1 \mathrm{MHz})$ sensor (PAC MICROPHONE $\mu 80$ ), a

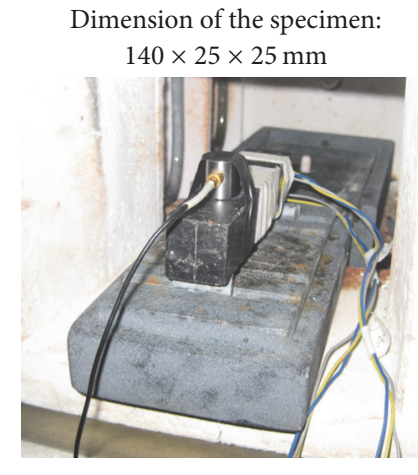

(a)
Dimension of the specimen: $140 \times 25 \times 25 \mathrm{~mm}$

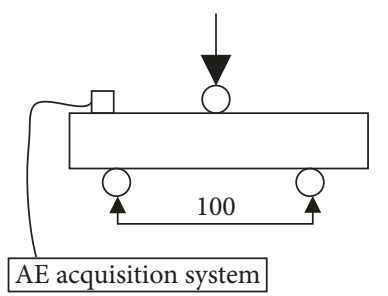

(b)
FIGURE 2: Experimental setup for three-point bend test at room temperature. (a) The physical diagram and (b) the schematic one. The AE sensor is fixed on the specimen through the adhesive tape. The pressure actuating pressure head is imposed on the middle of the specimen.

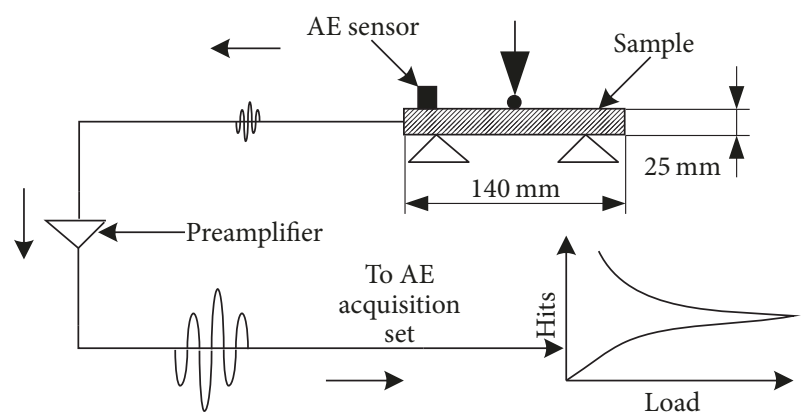

FIGURE 3: Experimental setup used for acoustic emission measurements [12].

preamplifier (EPA 1220A), and an acquisition card associated with a computer (AEDSP-32/16 MISTRAS digital system from Physical Acoustics Corporation). The AE sensor is a major element of the chain of acquisition because it collects the whole of the signals induced by the elastic waves created within the material whose amplitudes are higher than a fixed threshold in order to amplify and to record them. This system records the waveform and the main feature parameters well known in AE study such as count, hit, rise time, duration of hit, count to peak, and amplitude (in dB). Figure 4 presents different $\mathrm{AE}$ features extracted from the signal waveform.

4.2. PCA Parameter Reduction. The AE damage signals of the $\mathrm{Mg}-\mathrm{O}$ refractory during the three-point bend test were collected and 15 parameters were directly obtained: rise time $\left(X_{1}\right)$, count $\left(X_{2}\right)$, energy $\left(X_{3}\right)$, duration $\left(X_{4}\right)$, amplitude $\left(X_{5}\right)$, mean frequency $\left(X_{6}\right)$, RMS $\left(X_{7}\right)$, ASL $\left(X_{8}\right)$, peak frequency 


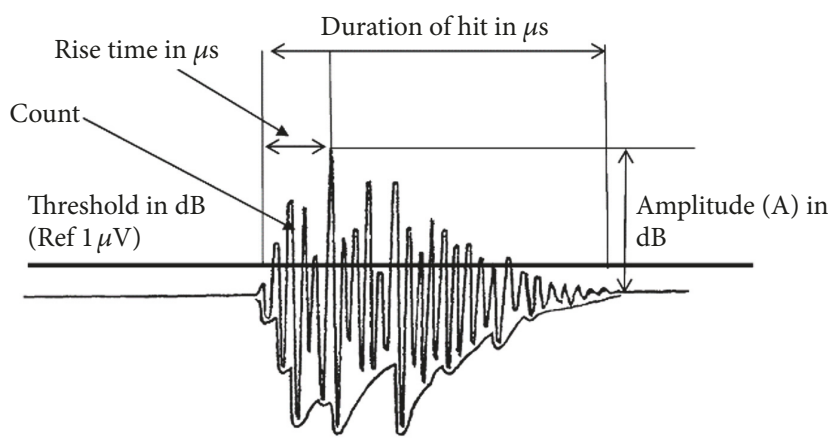

FIgURE 4: Typical AE features extracted from the recorded signal (hit) [12].

$\left(X_{9}\right)$, inverse calculation frequency $\left(X_{10}\right)$, original frequency $\left(X_{11}\right)$, signal strength $\left(X_{12}\right)$, absolute energy $\left(X_{13}\right)$, centroid frequency $\left(X_{14}\right)$, and peak frequency $\left(X_{15}\right)$. The number of the sample signals was 11168 and the observation matrix was $11168 \times 15$. In order to eliminate the disturbance of dimensionless parameter, the observation sample matrix was normalized before the principal component analysis and the data values were normalized to $(0,1)$. The covariance matrix's eigenvalues are shown in Table 2 . The cumulative contribution rate of each principal component was shown in Table 3. It can be seen from the table that the cumulative contribution rate of the first two principal components is $90 \%$, which is far greater than $85 \%$, meaning the first two principal components are sufficient enough to replace the overall clustering index. Therefore, the new principal components are produced and the number of the parameters is reduced from 15 to 2 .

4.3. Classification of the Damage Signals. For the application of GMM classification of the damage signals of the refractory, the increase in the number of the model can improve the accuracy of the model, however with increased complexity of the model, as discussed by Jiang et al. [24]. The Bayesian information criterion (BIC) has the ability to maintain the balance between the accuracy and complexity of the model; therefore, it is adopted to classify the damage.

$$
\mathrm{BIC}=-2 \ln L+k \ln T,
$$

where $L$ is the maximum of the likelihood function of the estimated model, $T$ is the number of observations, and $k$ is the number of the free parameters to be estimated in each GMM.

When the number of the model is increased from $M$ to $M+1$, the changing rate of the BIC is

$$
\xi_{M+1}=\frac{\mathrm{BIC}_{M}-\mathrm{BIC}_{M+1}}{\mathrm{BIC}_{M}} \times 100 \% .
$$

The changing rate of the BIC reflects the sensitivity of the $\mathrm{BIC}$ values to the number of the models. When the number of the models is increased from $M$ to $M+1$, the change rate of the BIC is large, which means that the number $M$ is insufficient in the description of the original data set accuracy and should be increased to $M+1$. When the change rate of the $\mathrm{BIC}$
TABLE 2: Eigenvalues of covariance matrix.

\begin{tabular}{lc}
\hline Parameter & Value \\
\hline$\lambda_{1}$ & 9.13 \\
$\lambda_{2}$ & 6.68 \\
$\lambda_{3}$ & 0.71 \\
$\lambda_{4}$ & 0.36 \\
$\lambda_{5}$ & 0.31 \\
$\lambda_{6}$ & 0.16 \\
$\lambda_{7}$ & 0.06 \\
$\lambda_{8}$ & 0.031 \\
$\lambda_{9}$ & $5.2 \times 10^{-3}$ \\
$\lambda_{10}$ & $3.3 \times 10^{-3}$ \\
$\lambda_{11}$ & $7.5 \times 10^{-4}$ \\
$\lambda_{12}$ & $1.6 \times 10^{-4}$ \\
$\lambda_{13}$ & $8.2 \times 10^{-5}$ \\
$\lambda_{14}$ & $4.0 \times 10^{-6}$ \\
$\lambda_{15}$ & $1.5 \times 10^{-6}$ \\
\hline
\end{tabular}

TABLE 3: Accumulated contribution rate of each component.

\begin{tabular}{lc}
\hline Principle component index & Cumulative contribution\% \\
\hline 1 & 52.3135 \\
2 & 90.6189 \\
3 & 94.6705 \\
4 & 96.7067 \\
5 & 98.5072 \\
6 & 99.432 \\
7 & 99.7786 \\
8 & 99.9456 \\
9 & 99.9756 \\
10 & 99.9943 \\
11 & 99.9986 \\
12 & 99.9995 \\
13 & 100 \\
14 & 100 \\
15 & 100 \\
\hline
\end{tabular}

is small, $M$ and $M+1$ have little difference in the description of the original data and $M$ is enough for the description.

The changing rate of the BIC is shown in Figure 5. It can be seen from the graph that when the number of the model is increased from 1 to 2 , the change of the BIC is significant, reaching $7 \%$. With the increase of the number of the models, the changing rate of the BIC gradually decreases $(<3 \%)$. Therefore, the model number of 2 is chosen to describe the observed data set.

The GMM operation results are shown in Figure 6. It can be seen from the plot that the damage signal is divided into two categories of $\omega_{1}$ and $\omega_{2}$, whose weights are 0.63 and 0.37 , respectively.

4.4. Verification. The Philips scanning electron microscopy (SEM, PSEM 500) and energy spectrometer (AMETEK) were 


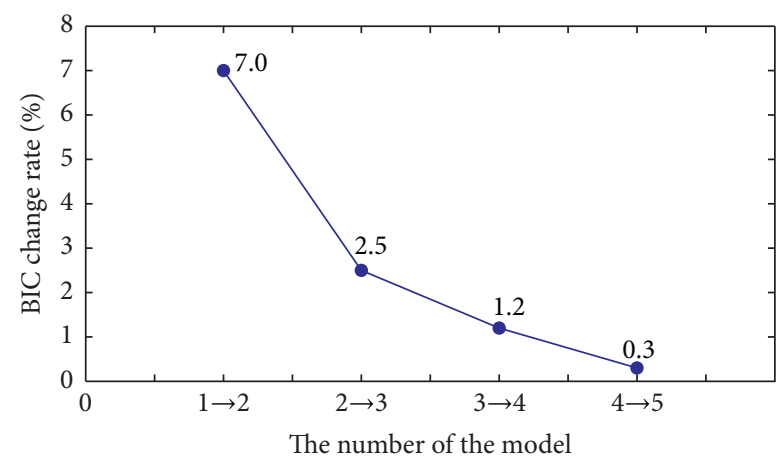

FIGURE 5: BIC change rate of each model number.

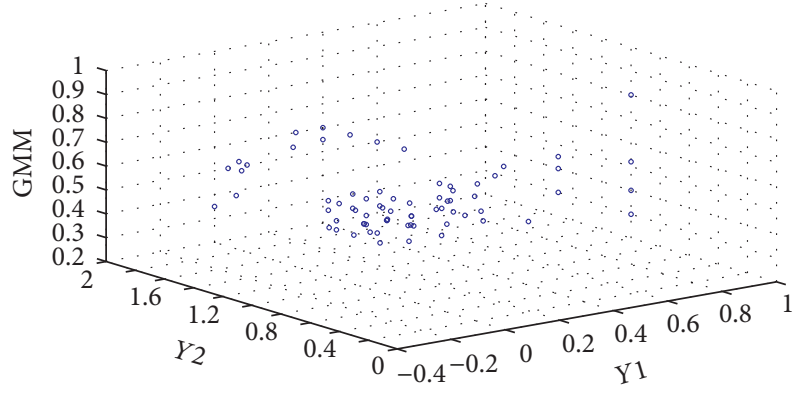

FIGURE 6: Computation results of the GMM algorithm $\left(\omega_{1}=0.63\right.$, $\left.\omega_{2}=0.37\right)$.

used for scanning analysis of the damage sample. The microscopic scanning results reveal that the damage forms were mainly the matrix and the interphase damage, as shown in Figures 7 and 8, and the matrix damage accounted for the larger proportion. The energy spectra results of the two kinds of microdamage are shown in Figures 9 and 10, respectively. It can be seen from Figure 9 that the main component of the matrix damage area is $C$ with the mass fraction of $97 \%$ and the crack can be regarded as the matrix crack. From Figure 10, the composition of the observation area near the interface was $\mathrm{C}$ with the mass fraction of $65 \%$ and $\mathrm{O}$ and $\mathrm{Mg}$ with the mass fraction of $15 \%$ and $18 \%$, respectively, which indicates that the matrix and the particle phase existed in the area and the crack is the interfacial crack. The SEM results show that the main damage form of the $\mathrm{MgO}-\mathrm{C}$ refractory is the matrix and the interface damage and the matrix phase damage accounted for the larger proportion. Therefore, the classification results using the method of the PCA and GMM are verified.

\section{Conclusions}

In this paper, a new $\mathrm{AE}$ data processing method of merging the similar parameters in the description of damage to reduce the dimension was developed. In the proposed method, the AE damage signals of the $\mathrm{Mg}-\mathrm{O}$ refractory during the three-point bend test were collected and 15 parameters were directly obtained: rise time $\left(X_{1}\right)$, count $\left(X_{2}\right)$, energy $\left(X_{3}\right)$, duration $\left(X_{4}\right)$, amplitude $\left(X_{5}\right)$, mean frequency $\left(X_{6}\right)$, RMS $\left(X_{7}\right)$, ASL $\left(X_{8}\right)$, peak frequency $\left(X_{9}\right)$, inverse calculation

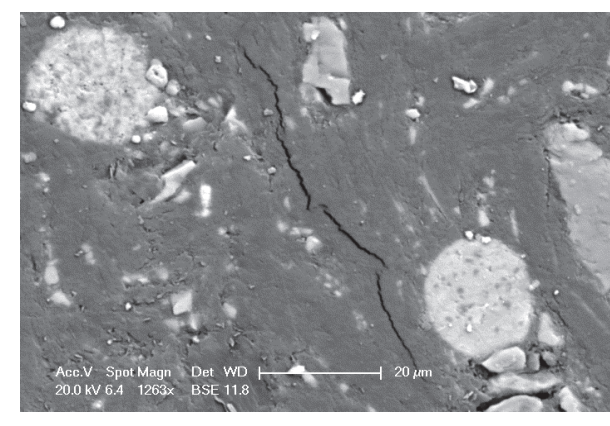

FIgURE 7: The matrix damage crack.

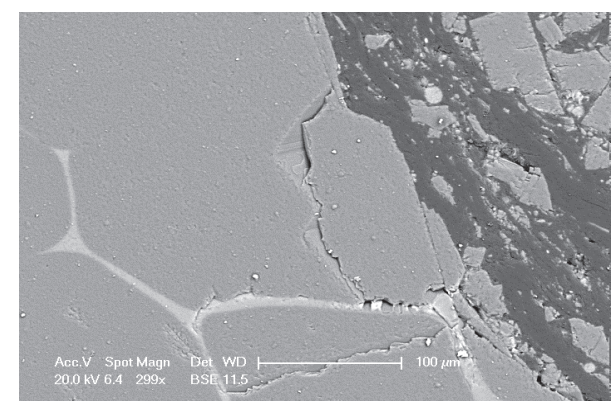

Figure 8: The interface damage crack.

frequency $\left(X_{10}\right)$, original frequency $\left(X_{11}\right)$, signal strength $\left(X_{12}\right)$, absolute energy $\left(X_{13}\right)$, centroid frequency $\left(X_{14}\right)$, and peak frequency $\left(X_{15}\right)$. The observation sample matrix was firstly normalized before the principal component analysis and the data values were normalized to $(0,1)$. The cumulative contribution rate of each principal component was calculated to successfully select the first two principal components of $90 \%$ contribution. Therefore, the new principal components were produced and the number of the parameters was reduced from 15 to 2 .

Then the Gaussian mixture model was used to classify the damage of the refractory according to the 2 damage indexes, which could be utilized to describe the overall damage property without linear dependence. Afterwards, the damage was classified into two major categories of $\omega_{1}$ and $\omega_{2}$ with the damage weight of $63 \%$ and $37 \%$, respectively. In order to verify the proposed method, the Philips scanning electron microscopy and energy spectrometer were used for scanning analysis of the sample. The scanning results showed that the damage form was indeed observed as 2 damage forms of mainly the matrix and the interphase damage. The main component of the matrix damage area was $\mathrm{C}$ with the mass fraction of $97 \%$. In the interface damage crack area, $\mathrm{C}$ was with the mass fraction of $65 \%$, and $\mathrm{O}$ and $\mathrm{Mg}$ were with the mass fraction of $15 \%$ and $18 \%$, respectively, which indicated that the matrix and the particle phase existed in the area and the crack was the interfacial crack. At last, the SEM results showed that the main damage form of the $\mathrm{MgO}-\mathrm{C}$ refractory was the matrix and the interface damage and the matrix phase damage accounted for the larger proportion. 


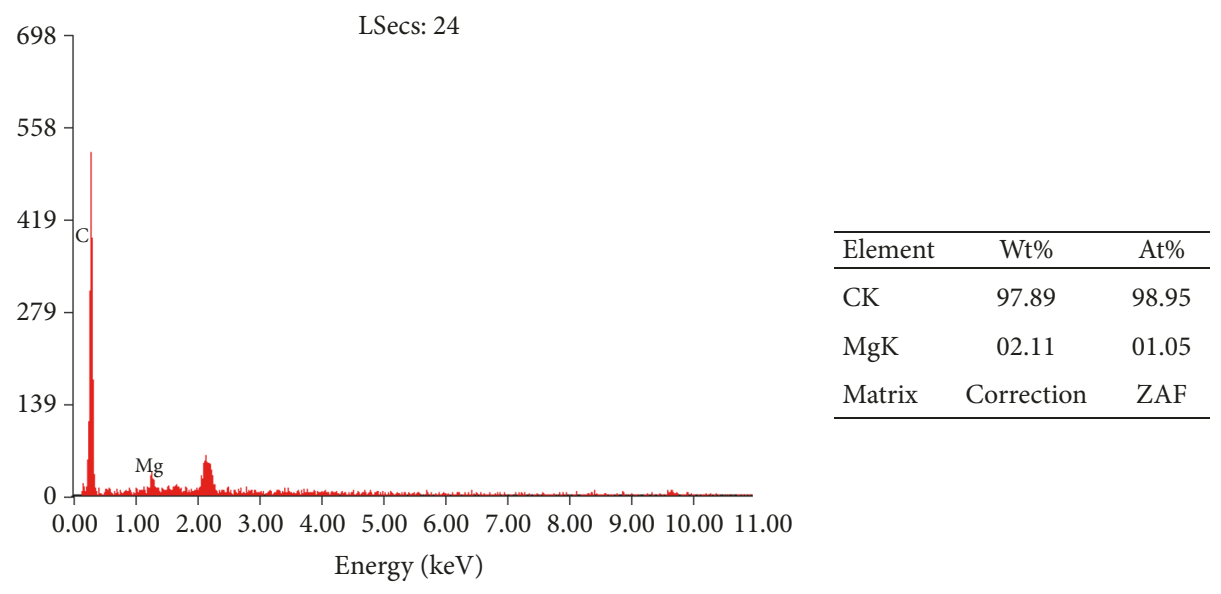

FIGURE 9: EDS analysis of the matrix damage crack.

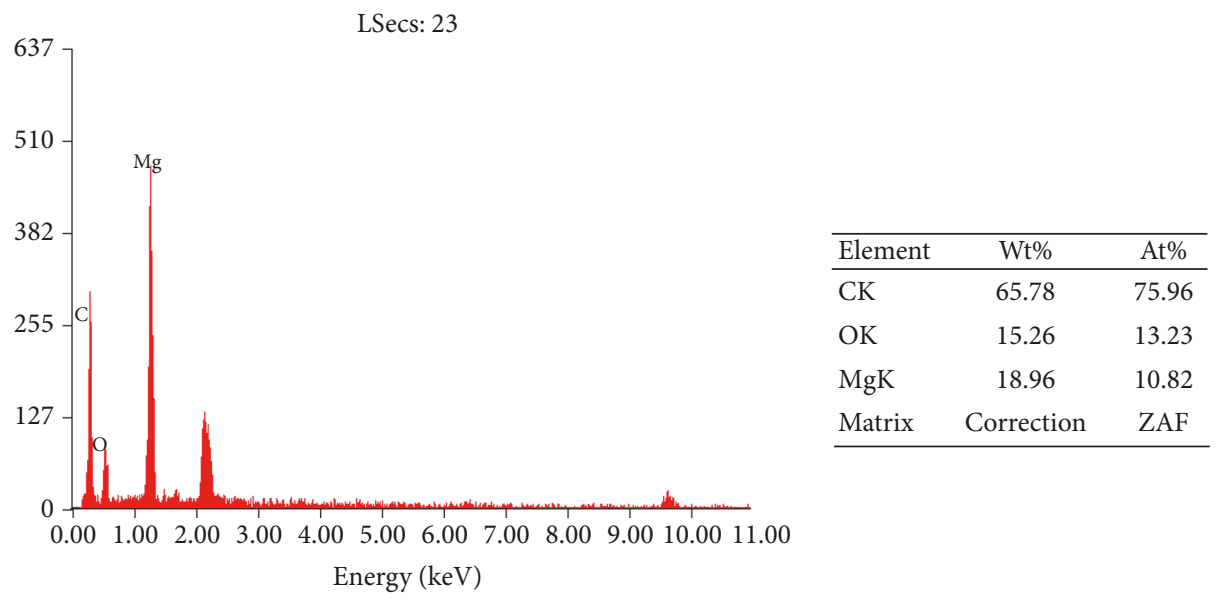

FIGURE 10: EDS analysis of the matrix damage crack.

Therefore, the classification results using the method of the PCA and GMM were verified.

\section{Conflicts of Interest}

The authors declare no conflicts of interest.

\section{Authors' Contributions}

Changming Liu and Zhigang Wang conceived and designed the experiments; Changming Liu performed the experiments; Dan Yang analyzed the data; Changming Liu, Zengbing $\mathrm{Xu}$, and Gangbing Song contributed to materials/ analysis tools development; Changming Liu, Zhigang Wang, and Gangbing Song wrote the paper.

\section{Acknowledgments}

The authors would like to thank the National Natural Science Foundation of China $(51505346,51375354$, and 51405353), the Natural Science Foundation of Hubei Province (2014CFB825), and the Open Foundation of the State Key
Laboratory of Refractories and Metallurgy for financial support.

\section{References}

[1] P. Selva, O. Cherrier, V. Budinger, F. Lachaud, and J. Morlier, "Smart monitoring of aeronautical composites plates based on electromechanical impedance measurements and artificial neural networks," Engineering Structures, vol. 56, pp. 794-804, 2013.

[2] D. M. Peairs, G. Park, and D. J. Inman, "Improving Accessibility of the Impedance-Based Structural Health Monitoring Method," Journal of Intelligent Material Systems and Structures, vol. 15, no. 2, pp. 129-139, 2016.

[3] S. Ritdumrongkul, M. Abe, Y. Fujino, and T. Miyashita, "Quantitative health monitoring of bolted joints using a piezoceramic actuator-sensor," Smart Materials and Structures, vol. 13, no. 1, pp. 20-29, 2004.

[4] Y.-K. An and H. Sohn, "Integrated impedance and guided wave based damage detection," Mechanical Systems and Signal Processing, vol. 28, pp. 50-62, 2012.

[5] G. Lu, Y. Li, T. Wang et al., "A multi-delay-and-sum imaging algorithm for damage detection using piezoceramic 
transducers," Journal of Intelligent Material Systems and Structures, vol. 9, pp. 1-10, 2016.

[6] H. Xiao, J. Zheng, and G. Song, "Severity evaluation of the transverse crack in a cylindrical part using a PZT wafer based on an interval energy approach," Smart Materials and Structures, vol. 25, no. 3, article 035021, 2016.

[7] T. Wang, G. Song, Z. Wang, and Y. Li, "Proof-of-concept study of monitoring bolt connection status using a piezoelectric based active sensing method," Smart Materials and Structures, vol. 22, article 87001, 2013.

[8] Q. Feng, Q. Kong, and G. Song, "Damage detection of concrete piles subject to typical damage types based on stress wave measurement using embedded smart aggregates transducers," Measurement, vol. 88, pp. 345-352, 2016.

[9] M. Ghassemi Kakroudi, E. Yeugo-Fogaing, M. Huger, C. Gault, and T. Chotard, "Influence of the thermal history on the mechanical properties of two alumina based castables," Journal of the European Ceramic Society, vol. 29, no. 15, pp. 3197-3204, 2009.

[10] C. Liu, Z. Wang, and Y. Li, "Innovative method on simulating the damage mechanism of the refractory," ISIJ International, vol. 53, no. 7, pp. 1275-1279, 2013.

[11] G. Briche, N. Tessier-Doyen, M. Huger, and T. Chotard, "Investigation of the damage behaviour of refractory model materials at high temperature by combined pulse echography and acoustic emission techniques," Journal of the European Ceramic Society, vol. 28, no. 15, pp. 2835-2843, 2008.

[12] C. Liu, Z. Wang, and Y. Li, "Damage pattern recognition and feature extraction of mgO-C refractory," ISIJ International, vol. 53, no. 7, pp. 1280-1285, 2013.

[13] N. Schmitt, Y. Berthaud, and J. Poirier, "Tensile behaviour of magnesia carbon refractories," Journal of the European Ceramic Society, vol. 20, no. 12, pp. 2239-2248, 2000.

[14] T. Chotard, J. Soro, H. Lemercier, M. Huger, and C. Gault, "High temperature characterisation of cordierite-mullite refractory by ultrasonic means," Journal of the European Ceramic Society, vol. 28, no. 11, pp. 2129-2135, 2008.

[15] C. Xu, P. Gong, J. Xie, H. Shi, G. Chen, and G. Song, "An acoustic emission based multi-level approach to buried gas pipeline leakage localization," Journal of Loss Prevention in the Process Industries, vol. 44, pp. 397-404, 2016.

[16] W. Li, S. C. M. Ho, D. Patil, and G. Song, "Acoustic emission monitoring and finite element analysis of debonding in fiber-reinforced polymer rebar reinforced concrete," Structural Health Monitoring, 2016.

[17] W. Li, Q. Kong, S. C. M. Ho et al., "Feasibility study of using smart aggregates as embedded acoustic emission sensors for health monitoring of concrete structures," Smart Materials and Structures, vol. 25, no. 11, article 115031, 2016.

[18] J. Vandenbussche, P. Lee, and J. Peuteman, "Round-Off Noise of Multiplicative FIR Filters Implemented on an FPGA Platform," Applied Sciences, vol. 4, no. 2, pp. 99-127, 2014.

[19] A. Martini, M. Troncossi, and A. Rivola, "Leak detection in water-filled small-diameter polyethylene pipes by means of acoustic emission measurements," Applied Sciences, vol. 7, no. 1, article 7010002, 2017.

[20] C. Liu, Z. Wang, Y. Li et al., "Damage pattern recognition of refractory materials based on bp neural network," LNCS, pp. 431-440, 2012.

[21] A.-B. A. E. Mohamad and Z. Chen, "Experimental and numerical analysis of the compressive and shear behavior for a new type of self-insulating concrete masonry system," Applied Sciences, vol. 6, no. 9, article 6090245, 2016.

[22] G. Lacidogna, P. Cutugno, G. Niccolini, S. Invernizzi, and A. Carpinteri, "Correlation between earthquakes and AE monitoring of historical buildings in seismic areas," Applied Sciences (Switzerland), vol. 5, no. 4, pp. 1683-1698, 2015.

[23] V. Christlein, D. Bernecker, F. Hönig, A. Maier, and E. Angelopoulou, "Writer Identification Using GMM Supervectors and Exemplar-SVMs," Pattern Recognition, vol. 63, pp. 258267, 2017.

[24] Q. Jiang, B. Huang, and X. Yan, "GMM and optimal principal components-based Bayesian method for multimode fault diagnosis," Computers \& Chemical Engineering, vol. 84, pp. 338-349, 2016.

[25] S. K. Al-Jumaili, K. M. Holford, M. J. Eaton, and R. Pullin, "Parameter Correction Technique (PCT): a novel method for acoustic emission characterisation in large-scale composites," Composites Part B: Engineering, vol. 75, pp. 336-344, 2015.

[26] R. Ahmed, A. Temko, W. Marnane, G. Lightbody, and G. Boylan, "Grading hypoxic-ischemic encephalopathy severity in neonatal EEG using GMM supervectors and the support vector machine," Clinical Neurophysiology, vol. 127, no. 1, pp. 297-309, 2016.

[27] M. A. Wright and B. D. Intwala, "The effect of elevated temperatures on the mechanical properties of B-Al composites," Journal of Materials Science, vol. 8, no. 7, pp. 957-963, 1973.

[28] R. Sharifi and R. Langari, "Nonlinear sensor fault diagnosis using mixture of probabilistic PCA models," Mechanical Systems and Signal Processing, vol. 85, pp. 638-650, 2017.

[29] H. Li, Z. Chen, Y. Sun, and H. . Karimi, "Stabilization for a class of nonlinear networked control systems via polynomial fuzzy model approach," Complexity, vol. 21, no. 2, pp. 74-81, 2015.

[30] X. Yuan, Z. Ge, H. Zhang, Z. Song, and P. Wang, "Soft sensor for multiphase and multimode processes based on Gaussian mixture regression," in Proceedings of the 19th IFAC World Congress on International Federation of Automatic Control, IFAC 2014, vol. 47, pp. 1067-1072, August 2014.

[31] H. C. Siu, J. A. Shah, and L. A. Stirling, "Classification of anticipatory signals for grasp and release from surface electromyography," Sensors, vol. 16, no. 11, article no. 1782, 2016.

[32] S. Hamel, A. Boulkroune, and A. Bouzeriba, "Function vector synchronization based on fuzzy control for uncertain chaotic systems with dead-zone nonlinearities," Complexity, vol. 21, no. S1, pp. 234-249, 2016.

[33] X. Zhao, W. Li, L. Zhou et al., "Application of support vector machine for pattern classification of active thermometry-based pipeline scour monitoring," Structural Control and Health Monitoring, vol. 22, no. 6, pp. 903-918, 2015.

[34] Q. Hou, W. Jiao, L. Ren, H. Cao, and G. Song, "Experimental study of leakage detection of natural gas pipeline using FBG based strain sensor and least square support vector machine," Journal of Loss Prevention in the Process Industries, vol. 32, pp. 144-151, 2014.

[35] C. Turgay, "Bayesian change detection based on spatial sampling and Gaussian mixture model," Pattern Recognition Letters, vol. 32, no. 12, pp. 1635-1642, 2011.

[36] B. Zhang, C. Zhang, and X. Yi, "Active curve axis Gaussian mixture models," Pattern Recognition, vol. 38, no. 12, pp. 23512362, 2005.

[37] J. Shang, M. Chen, H. Ji, and D. Zhou, "Recursive transformed component statistical analysis for incipient fault detection," Automatica, vol. 80, pp. 313-327, 2017. 
[38] American Standard, C1161, 2002. Standard Test Method for Flexural Strength of Advanced Ceramics at Ambient Temperature, ASTM International, West Conshohocken, PA, USA, 2002.

[39] A. Benavent-Climent, A. Gallego, and J. M. Vico, "An acoustic emission energy index for damage evaluation of reinforced concrete slabs under seismic loads," Structural Health and Monitoring, vol. 11, no. 1, pp. 69-81, 2012.

[40] D. G. Aggelis, D. V. Soulioti, E. A. Gatselou, N.-M. Barkoula, and T. E. Matikas, "Monitoring of the mechanical behavior of concrete with chemically treated steel fibers by acoustic emission," Construction and Building Materials, vol. 48, pp. 12551260, 2013.

[41] M. K. Elbatanouny, P. H. Ziehl, A. Larosche, J. Mangual, F. Matta, and A. Nanni, "Acoustic emission monitoring for assessment of prestressed concrete beams," Construction and Building Materials, vol. 58, pp. 46-53, 2014. 


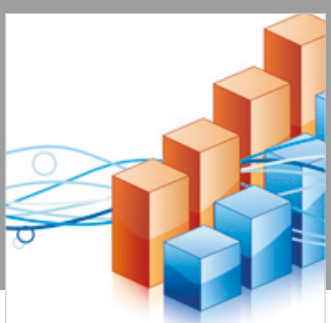

Advances in

Operations Research

\section{-n-m}
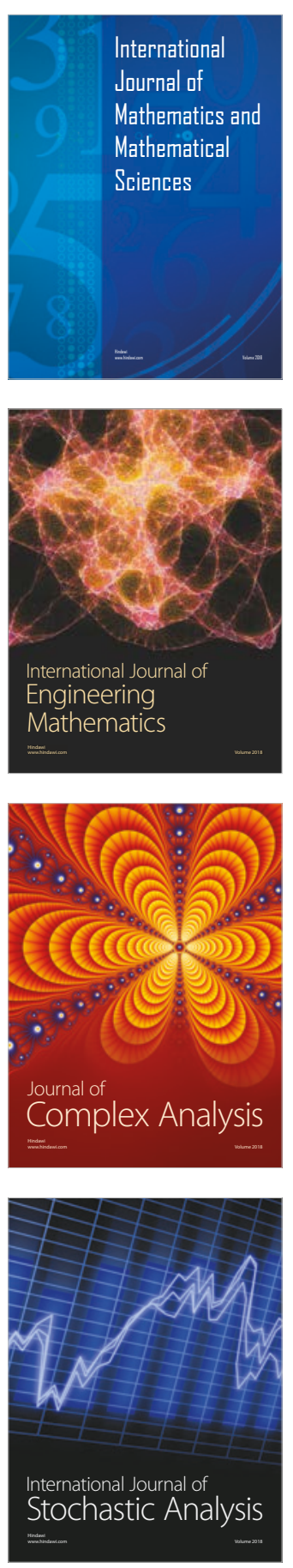
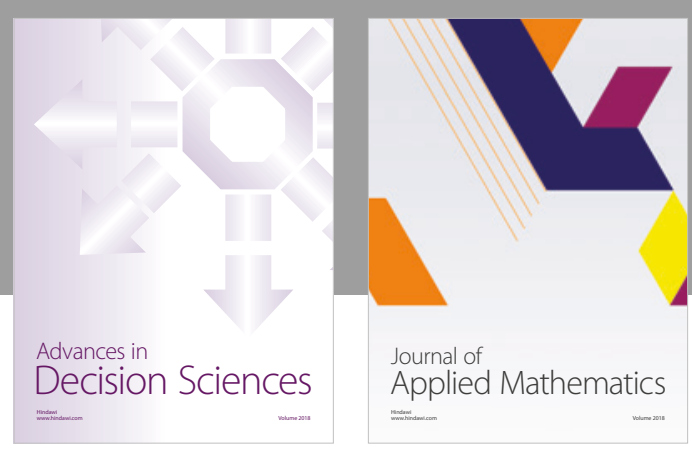

Journal of

Applied Mathematics
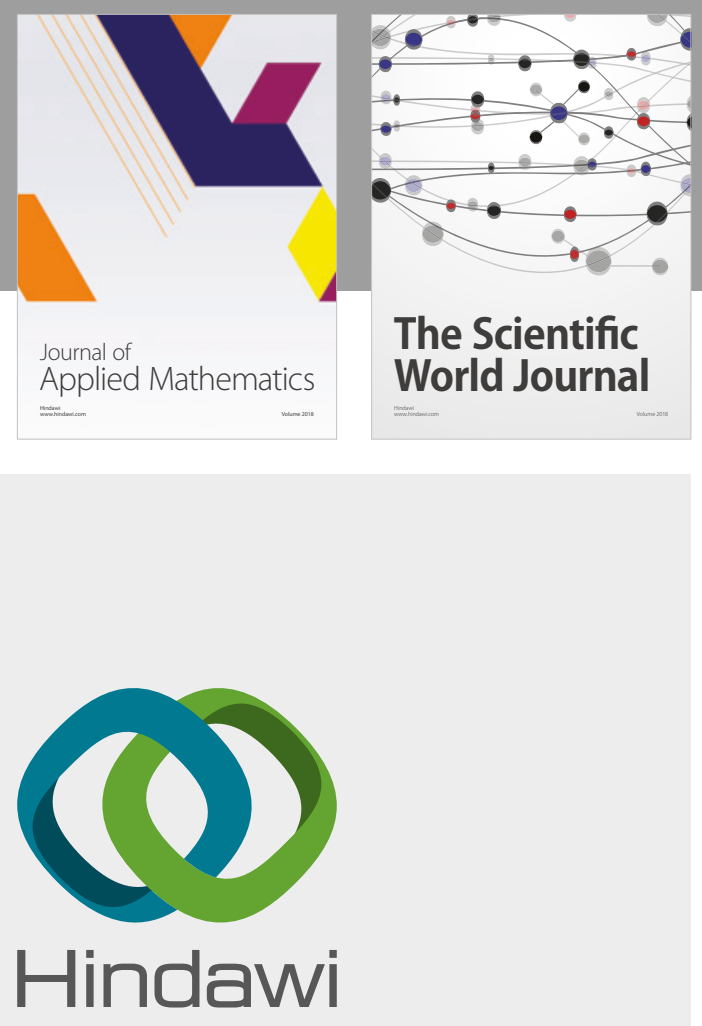

Submit your manuscripts at

www.hindawi.com

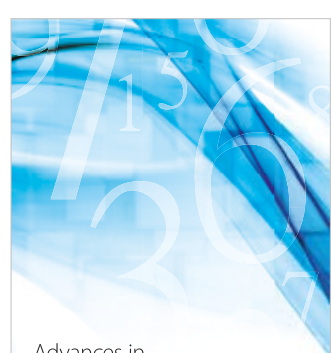

Advances in
Numerical Analysis
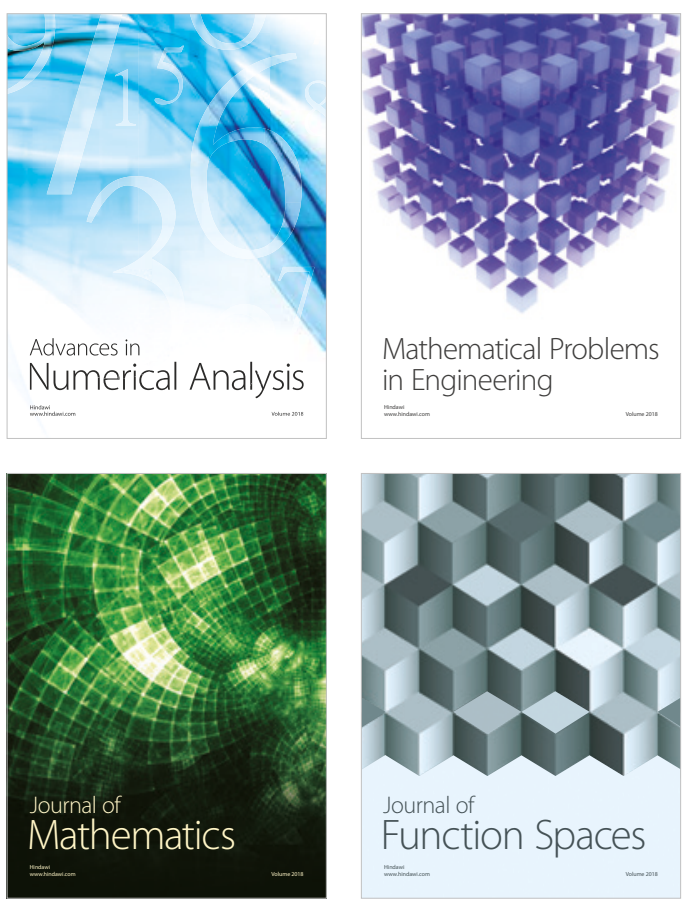

Mathematical Problems in Engineering

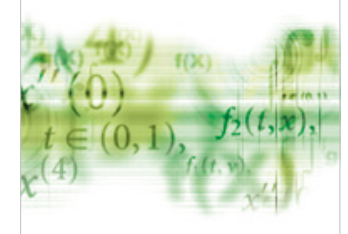

International Journal of

Differential Equations

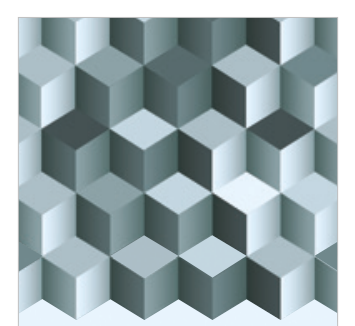

Journal of

Function Spaces
The Scientific

World Journal

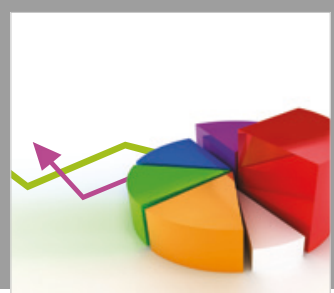

Journal of

Probability and Statistics
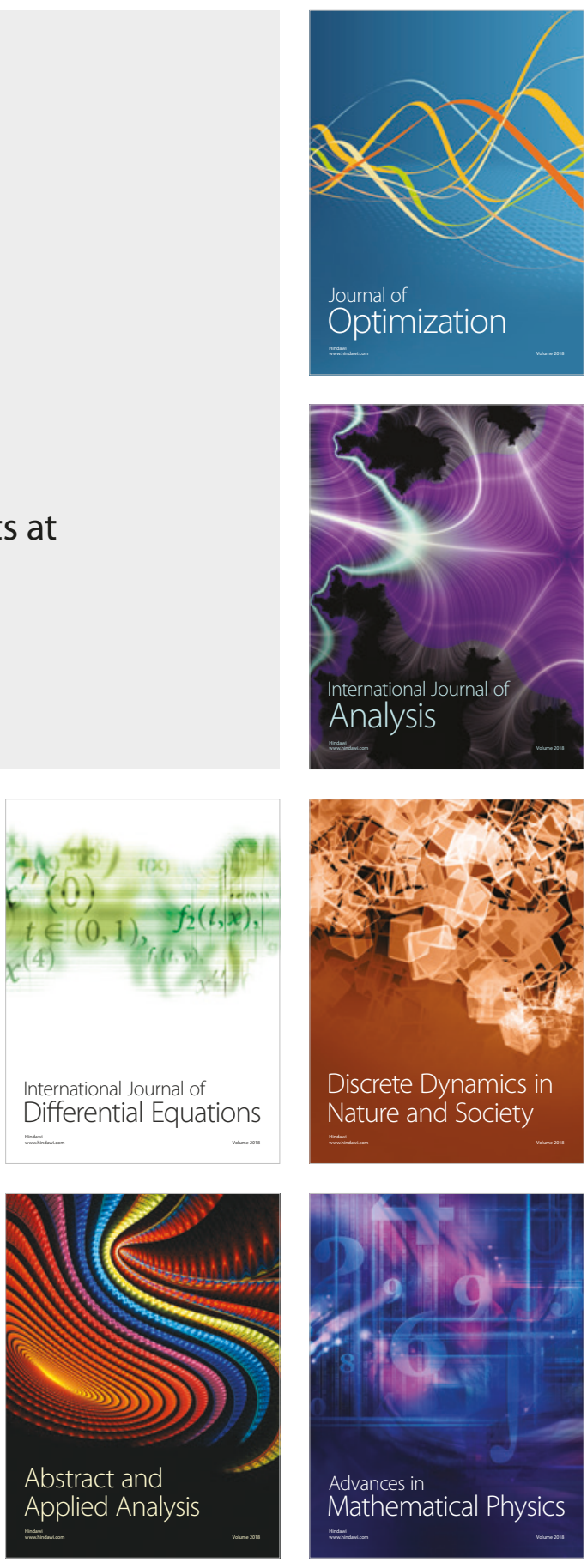